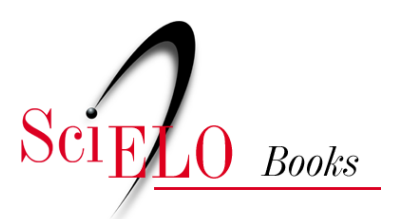

\title{
A força do desejo homoerótico interseccionado com questões de raça em Bom crioulo, de Adolfo Caminha
}

\author{
Rubenilson Pereira de Araujo
}

\section{SciELO Books / SciELO Livros / SciELO Libros}

ARAUJO, RP. A força do desejo homoerótico interseccionado com questões de raça em Bom crioulo, de Adolfo Caminha. In: MITIDIERI, AL., and CAMARGO, FP., orgs. Literatura, homoerotismo e expressões homoculturais [online]. Ilhéus, BA: Editus, 2015, pp. 241-264. ISBN 978-85-7455-442-6. Available from SciELO Books <http://books.scielo.org>.

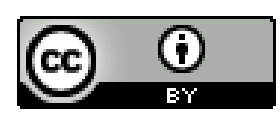

All the contents of this work, except where otherwise noted, is licensed under a Creative Commons Attribution $\underline{4.0 \text { International license. }}$

Todo o conteúdo deste trabalho, exceto quando houver ressalva, é publicado sob a licença Creative Commons Atribição 4.0.

Todo el contenido de esta obra, excepto donde se indique lo contrario, está bajo licencia de la licencia Creative Commons Reconocimento 4.0. 


\title{
A FORÇA DO DESEJO HOMOERÓTICO INTERSECCIONADO COM QUESTÕES DE RAÇA EM BOM CRIOULO, DE ADOLFO CAMINHA
}

\author{
Rubenilson Pereira de Araujo ${ }^{1}$
}

\begin{abstract}
Nunca experimentara semelhante cousa, nunca homem algum ou mulher produzira-lhe tão esquisita impressão, desde que se conhecia! Entretanto, o certo é que o pequeno, uma criança de quinze anos, abalara toda a sua alma, dominando-a, escravizando-a logo, naquele mesmo instante, como a força magnética de um imã (CAMINHA, 2009, p. 38).
\end{abstract}

Com as palavras textualmente citadas, inicia-se a trama central do romance Bom Crioulo, de Adolfo Caminha, publicado em 1895, mesmo ano em que o escritor irlandês Oscar Wilde foi condenado no tribunal inglês pela ousadia da vivência de "um amor que não

1 Doutorando em Letras: Ensino de Língua e Literatura pelo PPGL da Universidade Federal do Tocantins, onde é professor assistente no curso de Ciências Naturais (Biologia), ministrando as disciplinas concernentes ao campo pedagógico e linguístico. Desenvolve pesquisas sobre os estudos literários na perspectiva de gênero e diversidade sexual, sob a orientação do prof. Dr. Flávio Camargo.

E-mail: 〈rubenilsonaraujo@uft.edu.br>. 
ousou dizer o nome"2. O romance de Caminha é considerado um marco nos estudos sobre o homoerotismo na literatura brasileira, como afirma o pesquisador e militante do movimento LGBT no Brasil, João Silvério Trevisan (2009, p. 9):

[...] num contexto eivado de contradições, Bom crioulo tornou-se o grande mito da literatura brasileira relacionada ao homoerotismo, pois nele aparece, pela primeira vez entre nós, um protagonista homossexual, dentro de uma relação homossexual também protagonística.

Desta forma, podemos afirmar que é "no fim do século XIX que, praticamente, se inaugura o tema da homossexualidade em nossas letras" (BEZERRA; SILVA, 2012, p. 184). A referida obra literária foi produzida no contexto da estética naturalista, influenciada pelo cientificismo da época, à maneira de Émile Zola, que visava expor as mazelas sociais atreladas a uma visão medicalizante. Nesta perspectiva, o homem é visto sob o prisma do determinismo biológico, fruto de seu meio sociocultural. A homossexualidade é representada como uma chaga, patologia instintiva do ser humano, a qual pode emergir em ambientes de homossociabilidades, passivel,

2 Menção à declaração de Oscar Wilde (1854-1900), importante dramaturgo, escritor e poeta irlandês na defesa de Alfred Douglas, seu ex-amante, perante a promotoria e o júri, ao ser solicitado, pelo promotor, para explicar o que significava o título de um poema de sua autoria. 
portanto, de contenção e repressão dos impulsos da natureza humana. Além disso,

[o] naturalismo trouxe o corpo e o sexo para a cena literária, substituindo o amor cortês, praticamente espiritual, das narrativas românticas. Estas mudanças, no entanto, não sinalizam que as personagens homossexuais foram tratadas fora da heteronormatividade. Podemos perceber este fato pelo fim ao qual elas foram destinadas: castigo, decadência, exclusão e morte (BEZERRA; SILVA, 2012, p. 179).

$\mathrm{Na}$ narrativa de Adolfo Caminha, temos dois personagens que protagonizam um relacionamento homoafetivo marcado pelo contraste de seus parceiros, em sua constituição física e origem étnico-racial. Amaro é um ex-escravo, fugitivo ainda em tempos de escravidão, vivendo atualmente no sistema sociocultural recém-libertário, ainda preso à vassalagem de suas origens, porém respeitado em seu meio social pela força física, aliada aos seus instintos, classificados como "animais". Ele se apaixona por Aleixo, um adolescente loiro, de olhos azuis, de personalidade submissa, de origem socioeconômica humilde (família de pescadores), afável e que vivia sob o estigma de não corresponder aos padrões de virilidade masculina e aos serviços físicos braçais, típicos de seu entorno social.

O cenário inicial do romance é o interior de um navio, uma corveta decadente em alto 
mar, pois ambos estavam a serviço da marinha. O ambiente de bordo é marcado pelo trabalho hostil e por uma vida sem privacidade. Este cenário possibilitaria que emergissem os mais diversos desejos libidinosos, no sentido de saciar o erotismo dos corpos masculinos que ali habitavam. O recrutamento de homens favorecia desejos homoeróticos e relações sexuais entre os seres que vivenciavam a solidão em alto mar. Neste sentido, podemos observar cenas de homossociabilidade diversas (SEDGWICK, 1988), marcadas pelos seus códigos específicos de pessoas analfabetas e que dependiam do trabalho braçal para sobreviver.

A corveta encontra-se em visivel declínio, juntamente com o serviço da marinha naquele contexto. O narrador nos dá inicialmente uma descrição lúgubre desse ambiente sombrio:

A velha e gloriosa corveta que pena! já nem sequer lembrava o mesmo navio d'outrora, sugestivamente pitoresco, idealmente festivo, como um galera de lenda, branca e leve no mar alto, grimpando serena o corcovo das ondas!... (CAMINHA, 2009, p. 25).

O ambiente descrito antecipa o desfecho de um enredo trágico, devido à ênfase na descrição mórbida, decadente e agourenta do cenário. Essa descrição termina no fim do terceiro parágrafo com um sinal de reticências, possivelmente indicando ao leitor que por mais precisa que pudesse ser a descrição da decadência, ainda não retrataria toda a hostilidade 
presente no ambiente que antes foi cenário de glórias e vivacidades.

Ainda no início da narrativa, podemos acompanhar que, em meio à convivência interpessoal, tipicamente masculina, as personalidades, consideradas "diferentes" em suas homossociabilidades interpessoais, são veementemente rechaçadas, estereotipadas com atribuição de nomes pejorativos e também excluídas por palavras de injúrias ou difamações específicas do meio denominado de "macho" pelos operários da marinha.

A injúria atribuida aos atos desviantes cometidos pela heteronormatividade naturaliza a homofobia no local e faz com que as personagens vivenciem "a experiência do insulto (sem falar até da agressão física) [sendo] um dos traços mais comuns de suas existências" (ERIBON, 2008, p. 30). A discriminação verbal é uma forma de apontar a diferença porque o corpo é representado como um objeto passivel de injúria e castigos físicos.

Desta maneira, em um ambiente marcado por violências físicas, assemelhandose a um suposto sadomasoquismo, podemos acompanhar a sentença promulgada por um ato ilicito de um corpo:

Ora, aconteceu que, na véspera desse dia, Herculano foi surpreendido, por outro marinheiro, a praticar uma ação feia e deprimente do caráter humano. Tinham-no encontrado sozinho, junto à amurada, em pé, a mexer com o braço numa posição torpe, 
cometendo, contra si próprio, o mais vergonhoso dos atentados (CAMINHA, 2009, p. 33).

A cena pela qual o personagem Herculano será punido sugere um ato de masturbação, o qual era passivel de vigilância e punição, segundo o contrato social de convivência estabelecido no ambiente em questão. Notamos, portanto, o caráter de vigiar e punir os corpos a fim de adestrá-los (FOUCAULT, 2006), contendo os seus impulsos instintivos para continuar sendo um corpo dócil ao sistema de produção do trabalho na marinha. O narrador adjetiva essa ação natural como "feia", "deprimente do caráter humano" e o "mais vergonhoso dos atentados". Sequenciando a narrativa, defrontamo-nos com outras descrições, como:

[...] No convés brilhava a nódoa de um escarro ainda fresco: Herculano acabava de cometer um verdadeiro crime não previsto nos códigos, um crime de lesa natureza, derramando inutilmente no convés seco e estéril, a seiva geradora do homem (CAMINHA, 2009, p. 33).

Nestas descrições, podemos perceber nitidamente a visão reducionista da sexualidade humana, concebida apenas com fins para a reprodução da espécie, inviabilizando a possibilidade de se enxergar, no ato sexual, a possibilidade de prazer, deleite ou realização de base erótica do corpo. Na continuidade das seções públicas de torturas físicas 
dos corpos, os quais são milimetricamente sentenciados (150 chibatadas), esta situação vivenciada pelos personagens em questão no interior do navio nos leva a crer que objetiva à produção de mão de obra "barata" para o sistema servil da marinha em decadência, afinal, "o controle disciplinar dos corpos e dos gestos leva à produção de corpos dóceis, de corpos inteligiveis" (CAMARGO, 2013, p. 15). Notamos que, em cada ato e/ou ritual solene de punição, há a confissão verbal expressa pelo acusado do por que da pena recebida. Este fato nos remonta ao que Foucault discorre sobre a confissão dos sujeitos, prática estabelecida pelos dogmas da Igreja Católica, corrente nos séculos XVIII e XIX.

$\mathrm{Na}$ sequência, aparece o nosso protagonista "Amaro", como o terceiro a ser torturado pelas chibatadas por algum ato não condizente com os códigos de convivência em alto mar. O narrador introduz o personagem descrevendo-o da seguinte forma:

Seguia-se o terceiro preso, um latagão de negro, muito alto e corpulento, figura colossal de cafre, desafiando, com um formidável sistema de músculos, a morbidez patológica de toda uma geração cadente e enervada, e cuja presença ali naquela ocasião, despertava grande interesse e viva curiosidade: era o Amaro, gajeiro da proa o BOM CRIOULO na gíria de bordo (CAMINHA, 2009, p. 35 - grifos do autor). 
Notamos, na descrição que entroniza o nosso protagonista na narrativa, a contradição em relação à adjetivação atribuída ao mesmo, ou seja, após as descrições de "figura colossal" e do "sistema de músculos", que despertam notoriedade pelos demais, ele é denominado como "Bom Crioulo", provavelmente devido aos seus atributos psicológicos de urbanidade, em virtude da domesticação e/ou adestramento que a dita "civilização branca" impôs a ele para a convivência social. Entretanto, segundo o desenrolar da narrativa, o mesmo é impelido por uma força descomunal quando ingere bebidas alcóolicas.

Esse fato nos remonta à mitologia do "bom selvagem" , domesticado pela raça branca eurocêntrica, que marca o seu lugar hegemônico na classificação da raça negra/indigena como subalterna e inferior. Na demarcação da identidade, notamos, nesse contexto exemplificado, que há o marco de uma relação de poder, onde o primeiro é detentor da condição de dominador e o outro é colocado à margem, na condição de dominado, relegado ao patamar de inferioridade.

Em toda a trama narrativa, notamos os corpos sendo punidos fisicamente a fim de

30 suíço Jean-Jacques Rousseau, filósofo e escritor de origem francesa, conviveu com os maiores expoentes do Iluminismo. Ele é considerado o precursor do Romantismo pela criação do mito do "bom selvagem". Convencido de que o homem é bom por natureza, sendo o viver em sociedade a causa da sua degradação moral, passou a condenar o estudo das ciências e a prática das artes. Privilegiando o naturalismo, o primitivismo e os costumes indígenas, tornou-se um implacável crítico da organização social. 
serem adestrados, tornando-os úteis e servis. Historicamente, os castigos focalizam como objeto o corpo, com a intenção de controlar suas forças para atender o ideal preconizado, pois

as relações de poder têm alcance imediato sobre ele; elas o investem, o marcam, o dirigem, o supliciam sujeitam-no a trabalhos, obrigam-no a cerimônias, exigem-lhe sinais (FOUCAULT, 1997, p. 28)

porque, mediante tais práticas, "o corpo só se torna útil se é ao mesmo tempo, produtivo e corpo submisso" (FOUCAULT, 1997, p. 28). Podemos afirmar ainda que, na narrativa em questão, "o flagelo do corpo dos sentenciados indica que privilegiar os prazeres da carne é um mau caminho e merece castigo" (BEZERRA; SILVA, 2012, p. 180).

A causa que levou Amaro à prisão e à execução do castigo foi justamente seu interesse pelo grumete Aleixo:

O motivo, porém, de sua prisão agora, no alto mar, a borda da corveta, era outro, muito outro: Bom-Crioulo esmurrara desapiedadamente um segunda-classe, porque este ousara, sem o seu consentimento, maltratar o grumete Aleixo, um belo marinheirito de olhos azuis, muito querido por todos e de quem diziam-se cousas (CAMINHA, 2009, p. 37). 
Neste momento da narrativa, acompanhamos o sofrimento de Amaro, o qual é submetido, no final do primeiro capítulo, a um total preciso de 150 chibatadas, embora tal martírio the causasse certo prazer devido ao fato de essa pena ser em virtude do objeto de seu desejo erótico - Aleixo, o qual ainda não aparece na narrativa, mas apenas é mencionado pelo narrador que o insere posteriormente. Aleixo, introduzido na narrativa como prestador de serviços tipicamente femininos, sendo proveniente do sul do estado de Santa Catarina, é representado como o arquétipo oposto de Amaro, o qual já nutre sentimentos de afeto por ele, desde o primeiro encontro. Vale ressaltar que a homossexualidade sugerida visivelmente nos traços do personagem é tratada como "diziam-se cousas", ou seja, prevalece "o recurso do indizivel" (BEZERRA; SILVA, 2012) do provável relacionamento amoroso "que não ousará dizer o nome", devido à deslegitimação sociocultural vigente.

A atração física dos amantes, envoltos em seções semelhantes ao sadomasoquismo, vivenciadas nas viagens a bordo da corveta, e a atração fatal entre os dois opostos, em sua estrutura corpórea, continua até culminar no ato sexual em si, onde podemos notar, explicitamente, o tratamento da visão patologizante acerca da homossexualidade:

Uma sensação de ventura infinita espalhava-se-lhe em todo o corpo. Começava a sentir no próprio sangue impulsos nunca experimentados, 
uma como vontade ingênita de ceder aos caprichos do negro, de abandonar-se-lhe para o que ele quisesse uma vaga distensão dos nervos, um prurido de passividade. . .

- Ande logo! murmurou apressadamente, voltando-se.

E consumou-se o delito contra a natureza (CAMINHA, 2009, p. 30 - grifo nosso).

Como percebemos nessa citação, o ato (homo)sexual é descrito assemelhando-se a um rito de iniciação que se dá pela culminância do desejo erótico entre os corpos que se veem conduzidos por uma força instintiva até culminar na ação de enlace sexual. Porém o autor a nomeia explicitamente de "delito contra a natureza”. Notamos nitidamente, nessa passagem, a força de noções socioculturais de uma sociedade que não consegue conceber o desejo erótico e sexual entre pessoas do mesmo sexo. Podemos notar, na concretização do ato em si, a fissura do que está arraigado socioculturalmente em relação ao binarismo estabelecido.

Na descrição anterior, notamos uma força instintiva levando Aleixo a uma postura passiva no ato sexual, como se uma força maior o detivesse ao ato de passividade. Tal leitura leva-nos ainda a refletir que o desejo íntimo encontra-se em um patamar superior à anatomia corpórea, a ponto de alterar a corrente sanguínea e deixar-se levar pela vontade que se mostra maior do que as prescrições socialmente estabelecidas. 
O início do relacionamento de Amaro com Aleixo faz desencadear o processo de regressão de um corpo dócil, moldado para atender ao sistema de produção militar e, gradativamente, o Bom Crioulo vai perdendo as destrezas e os bons costumes adquiridos no contato com a civilização:

[...] insinuavam que Bom-Crioulo tornara-se assim, esquecido e indiferente, dês que se metera com o Aleixo, o tal grumete, o belo marinheirito de olhos azuis, que embarcara no sul. O ladrão do negro estava mesmo ficando sem vergonha! (CAMINHA, 2009, p. 46).

Em meio aos olhares e às criticas vigilantes, a narrativa sobre o relacionamento de Amaro com Aleixo prossegue. O corpo de Aleixo vai sendo moldado por Amaro, com presentes e adornos, inclusive um dos primeiros presentes que Amaro oferece a Aleixo é um espelho "barato", o que o faz sentir-se feliz com a sua autoimagem refletida. Este fato remonta-nos à analogia com o mito de $\mathrm{Narciso}^{4}$, pois Aleixo assume a sua beleza fisica segundo os padrões socioculturais vigentes. Amaro promete-lhe coisas boas, gabase de "conhecer o mundo" e lhe faz interessantes promessas para quando chegarem à cidade do Rio de Janeiro, como passeios no teatro, no

\footnotetext{
40 mito de Narciso representa (senão para os gregos ao menos para nós) o drama da individualidade"; "ele mostra, isto sim, a profundidade de um indivíduo que toma consciência de si mesmo" em si mesmo e perante a si mesmo, ou seja, no Lugar onde experimenta os seus dramas humanos (SPINELLI, 2006, p. 99).
} 
Pão de Açúcar, nos casarões, nos palácios etc., incluindo-se a promessa de morarem juntos na Rua da Misericórdia. Estas promessas de Amaro a Aleixo nos remetem ao imaginário sociocultural do relacionamento homoerótico marcado por bonificações financeiras, "o amor de bolso", como uma espécie de ressarcimento pelos afetos dispensados ao corpo homossexual.

Outro fato interessante é o deslocamento, a fuga do local restrito para a cidade a fim de vivenciar um amor proibido pelas normas heterossexuais. De acordo com Eribon (2008, p. 31-33), "a cidade sempre foi o refúgio dos homossexuais" e "a homossexualidade tem ligação com a cidade”. Seria como se a cidade possibilitasse uma convivência amorosa com mais privacidade íntima e menos vigilância e punição dos olhares alheios.

Ao deparar-se com o porto de chegada, destino dos amantes, na cidade do Rio de Janeiro, Amaro discorre sobressaltado pela força impetuosa de uma paixão, totalmente envolto em questionamentos de insegurança, fragilidade, e contradição a respeito dos sentimentos que nutre pelo ente amado e também acerca de seus desejos. Amaro, inclusive, se autoquestiona sobre a sua orientação sexual, atribuindo-lhe uma espécie de castigo, ato pecaminoso ou algo semelhante:

Ao pensar nisso Bom-Crioulo sentia uma febre extraordinária de erotismo, um delírio invencivel de gozo pederasta... Agora compreendia que só no homem, no próprio homem, ele 
podia encontrar aquilo que debalde procurara nas mulheres. Nunca se apercebera de semelhante anomalia, nunca em sua vida tivera a lembrança de perscrutar suas tendências em matéria de sexualidade. [...] E o mais interessante é que aquilo ameaçava ir longe, para mal de seus pecados... Não havia jeito, senão ter paciência, uma vez que a natureza impunha-lhe esse castigo [...] De qualquer modo estava justificado perante sua consciência, tanto mais quanto havia exemplos ali mesmo a bordo, para não falar em certo oficial de quem se diziam cousas medonhas no tocante à vida particular. Se os brancos faziam, quanto mais os negros! É que nem todos têm força para resistir: a natureza pode mais que a vontade humana... (CAMINHA, 2009, p. 66).

No excerto anterior, podemos perceber toda a concepção sociocultural a respeito da heterossexualidade compulsória, a qual impõe o binarismo como única alternativa para a orientação sexual do indivíduo. O que foge de tal destino seria a sexualidade desviante, atribuída à ideia de patologia e/ou transtorno psiquiátrico. Nessas reflexões, notamos a condição subalterna da raça negra, sempre considerada como vassala e dependente da hegemonia branca e tudo isso em contrapartida de um simples e natural desejo humano que aflora na personalidade de uma pessoa cônscia de 30 anos.

Em uma época marcada pela escravidão, 
a condição considerada inferior da raça negra condiciona Amaro, socialmente, a uma espécie de animalização. Ele se encontra em uma situação de subjetivação, absorto em seus conflitos interiores, os quais nos levam a concluir que ele "sempre é suscetivel de ser anulado, desvalorizado, ridicularizado ou simplesmente explicado e reduzido ao estado de objeto pelas categorias do discurso dominante" (ERIBON, 2008, p. 74). Tal fato acentua-se ainda mais na intersecção dos preconceitos raciais e de gênero, na condição de negro e homossexual, dupla estigmatização social, pois, na discriminação racial, o estigma está na pigmentação externa da pele, enquanto na orientação sexual, está o desejo interno, intrínseco ao sujeito.

No quinto capítulo da narrativa, o outro cenário onde se encontram os amantes (quarto alugado de D. Carolina, na Rua da Misericórdia, no Rio de Janeiro), semelhantemente ao primeiro ambiente onde se inicia a trama romanesca (a corveta), mais uma vez o ambiente decadente inspira certo agouro para o desfecho do caso de amor. Se aquele é comparado a um abutre, nesse, ronda a notícia de uma morte recente do ex-inquilino. Em certos momentos de descrição das cenas amorosas dos amantes homossexuais, notamos desejos animalizados e incomuns:

Uma cousa desgostava o grumete: os caprichos libertinos do outro. Porque Bom-Crioulo não se contentava em possuí-lo a qualquer hora do dia ou da noite, queria muito mais, obrigava 
-o a excessos, fazia dele um escravo, uma mulher-a-toa propondo quanta extravagância lhe vinha à imaginação. Logo na primeira noite exigiu que ele ficasse nu, mas nuzinho em pêlo: queria ver o corpo...

Dentro do negro rugiam desejos de touro ao pressentir a fêmea... Todo ele vibrava, demorando-se na idolatria pagã daquela nudez sensual como um fetiche diante de um símbolo de ouro ou como um artista diante duma obra-prima. Ignorante e grosseiro, sentia-se, contudo, abalado até os nervos mais recônditos, até às profundezas do seu duplo ser moral e físico, dominado por um quase respeito cego pelo grumete que atingia proporções de ente sobrenatural a seus olhos de marinheiro rude (CAMINHA, 2009, p. 78-80).

De modo geral, Amaro, enquanto individuo mais maduro, nutre por Aleixo um verdadeiro sentimento de encanto, fascinação e obsessão. Em contrapartida, provavelmente devido a uma suposta imaturidade ou inadaptação a tal prática sexual, a correspondência por parte de Aleixo não é tão reciproca. Um fato interessante a observar a respeito da representação da homossexualidade pelo narrador são as consequências de uma "heteronormatividade compulsória" (RICH, 1980), visto que a dualidade entre ativo versus passivo prevalece na narrativa, além da oposição da estrutura física dos corpos dos amantes, levando Amaro à verdadeira veneração pelos atributos frágeis e afeminados de seu parceiro Aleixo. 
O relacionamento e a atração física desencadeiam-se em analogia semelhante a uma relação homem/mulher e não entre dois corpos do mesmo sexo masculino:

Amaro trata Aleixo como se trata uma mulher; as caracteristicas que descreve e admira nele são atributos femininos [...] Ao contemplar o jovem, Amaro o vê como uma mulher, nunca como um homem; com o receio da traição de Aleixo, o negro pensa que o adolescente pudesse vir a traí-lo com outro homem, jamais com uma mulher (OLIVA, 2012, p. 220).

O narrador defende a tese de que os instintos de Amaro são selvagens e os seus desejos, considerados doentios, visto que ele é duplamente estigmatizado: negro e homossexual, na sociedade de final do século XIX, contradizendo o protótipo de indivíduo social e hegemonicamente aceito na época (e até nos dias atuais): branco, cristão, de classe média, de origem europeia e heterossexual. Amaro continuava trabalhando duro na corveta para manter as obrigações de provedor da casa, o seu corpo ia se definhando a cada dia, enquanto Aleixo, sempre muito bem cuidado, encorpava-se significativamente. Ele ia adquirindo dia a dia características mais masculinas, deixando de lado a sua feminilidade.

O que o Bom-Crioulo não sabia era a intenção da proprietária da casa, D. Carolina, que começava a planejar uma intervenção para o caso tornar-se um triângulo amoroso: 
Há dias metera-se-lhe na cabeça uma extravagância: conquistar o Aleixo, o bonitinho, toma-lo para si, tê-lo como amantezinho do seu coração avelhentado e gasto, amigar-se com ele secretamente, dando-lhe tudo quanto fosse preciso: roupa, calçados, almoço e jantar nos dias de folga dando-lhe tudo enfim (CAMINHA, 2009, p. 89).

D. Carolina projeta, no jovem Aleixo, a concretização de seus desejos eróticos, visto o mesmo mostrar-se ainda inexperiente e passível de modelá-lo como o amante ideal. Daí, ela planeja sua ação e, determinado dia, na ausência do Bom-Crioulo, após um passeio de Aleixo, concretiza a sua intenção no interior de seu quarto previamente preparado:

Entra, filhinho, entra, que isto aqui é nosso, isto aqui é da tua portuguesinha, não vês?

$\mathrm{E}$, alegre como nunca, foi abrindo as janelas que diziam para a Rua da Misericórdia, num alvoroço. Enquanto o pequeno andava fora, ela fizera nova toilette, penteara-se, mudara a roupa, trocara os tamancos por umas sapatinhas cor de sangue e colocara os anéis, os célebres anéis que lhe tinham querido roubar: transformarase completamente.

Senta, deixa de tolice, filho!

Aleixo sentou-se muito acanhado, com um ar de colegial que pela primeira vez penetra num lugar suspeito. [...]. O contato de sua perna com a 
da portuguesa produzia-lhe um calorzinho especial, um brando enleio d'alma, uma vaga e deliciosa canseira no fundo do ser, um esquisito bem-estar $[\ldots]$

O efebo teve um arranco de novilho excitado, e, segurando-se à cadeira com as mãos ambas, todo trêmulo agora $[\ldots]$

Então ela, como se lhe houvessem aberto de repente uma caudal de gozo, cravou os dentes na face do grumete, numa fúria brutal, e segurando-o pelas nádegas, o olhar cintilante, o rosto congestionado, foi depô-lo na cama (CAMINHA, 2009, p. 91-94).

Na descrição minuciosa desta cena, comparada com o primeiro ato sexual ocorrido entre o casal Amaro e Aleixo, notamos explicitamente atos de iniciação de um corpo nas práticas de sexualidade ativa, em que o narrador não poupa detalhes de um desejo erótico que sobressalta o ser humano, independentemente da orientação sexual, idade ou posição social. Em ambos os momentos (homossexual e heterossexual), Aleixo demonstra-se inexperiente em determinada prática sexual, apresentando nítidos traços de passividade e submissão aos desejos eróticos do/a parceiro/a.

Tais fatos indicam a constituição de uma narrativa de formação em que o grumete acaba incluso nas regras sociais heteronormativas que lhe são impostas, porque se envolveu com o sexo oposto e de origem racial semelhante à sua, passando a ter ojeriza íntima 
ao antigo parceiro sexual. Ao mesmo tempo, Aleixo permite observar facetas da diversidade sexual humana, a qual emerge numa provável bissexualidade da personagem, que estabelece a possibilidade de "trânsito de uma identidade de gênero para outra" (OLIVA, 2012, p. 217).

O triângulo amoroso prossegue às escondidas, mas quando Amaro volta do trabalho intenso na velha corveta, com saudades do amante, foge para o velho quarto da Rua da Misericórdia, a fim de reencontrá-lo, mas não o encontra em casa e, desapontado, começa a nutrir suspeitas de ciúmes pela possibilidade de um terceiro elemento do mesmo sexo no relacionamento homoerótico. Amaro envolve-se em confusões e/ou contendas devido à ingestão de bebidas alcoólicas, visto que toda vez que se embriagava, entrava em pleno descontrole de suas faculdades humanas. Envolveuse em lutas que duraram horas com a polícia, culminando em sua prisão, já bastante machucado fisicamente.

Bom-Crioulo, sentindo-se solitário e abandonado no ambiente hostil do hospital, ansiava pela visita de Aleixo que, porém, estava verdadeiramente enamorado pela portuguesa e satisfazia com ela as suas fantasias sexuais mais intimas. Ele sentia pena de Amaro, devido aos favores obtidos ao longo da vida, e, ao mesmo tempo, um verdadeiro nojo das intimidades vividas entre ambos. $\mathrm{O}$ hospital, para Amaro, assemelhava-se a um inferno, os dias eram longos e as noites, intermináveis. Os espaços reservados para o 
cenário do desenlace do romance são fechados, sombrios e se constituem como íntimos, privados do público em geral, pois

[assim] como a corveta e o quarto, o hospital é também um espaço de reclusão, pois todos estão localizados à distância do espaço público. Quando a relação vivida por eles chega à rua é para ter o seu fim decretado e selado com a morte. A rua é o cenário no qual as cortinas do teatro amoroso homoerótico se fecham (BEZERRA; SILVA, 2012, p. 183).

D. Carolina mesma foi quem impediu a comunicação entre Amaro e Aleixo, orientando esse a não visitar aquele cujo ressentimento se marca pelo desejo possessivo, doentio, uma espécie de "amódio" (misto de amor e ódio) que o interpela. Após fugir do hospital, quando chega à Rua da Misericórdia, "BomCrioulo ficou imóvel, calado, perdido nas suas ideias. Aleixo amigado com a portuguesa, com a D. Carolina! Era inacreditável, era um desaforo sem nome, um desrespeito, uma falta de vergonha, um escândalo!" (CAMINHA, 2009, p. 154). Quando os ex-amantes se encontram, o diálogo é tenso, presenciado por uma multidão que ignora o protagonista, e deixa o corpo ensanguentado do grumete inerte e sem vida. 


\section{Considerações finais}

O romance Bom Crioulo, de Adolfo Caminha (1895), é uma obra clássica, considerada pioneira nos estudos homoeróticos na literatura brasileira, devido ao fato de apresentar, na trama central, um relacionamento homoerótico. Prevalece em toda a narrativa uma reiteração da homossexualidade, compreendida e representada discursivamente a partir de um ponto de vista patológico, característico de uma época marcada pelo cientificismo e pela descoberta das mazelas sociais na estética literária denominada Naturalismo.

Além disso, podemos verificar o posicionamento discriminatório e preconceituoso do narrador, assim como os valores depreciativos referentes às práticas discursivas de subjetivação dos dois personagens. Nesse sentido, a homossexualidade é associada a uma perspectiva pejorativa a partir de um processo de subalternização dos personagens homoafetivos, cujo desejo é alijado na e pela sociedade da época, impondo a Amaro e a Aleixo uma degradação moral e social.

$\mathrm{Na}$ trama do romance, verificamos um mundo de injúrias, destinado aos corpos dos personagens homossexuais, objetos de poder e de manipulação. Além disso, a intersecção de estigmas de gênero e raça, sofridos por Amaro, o qual é duplamente estigmatizado pelas condições de ser negro e homossexual em uma sociedade hipócrita, regulada pelo preconceito explícito e pelas normas de uma heterossexualidade compulsória. 


\section{REFERÊNCIAS}

BEZERRA, Carlos Eduardo; SILVA, Telma Maciel. Os destinos das personagens homossexuais: recortes no panorama literário brasileiro do final do século XIX ao início do século XX. In: MOREIRA, Adailson, BEZERRA, Carlos Eduardo; SILVA, Telma Maciel da (Org.). Arco-íris revisitado: diversidade sexual em pauta. Porto Alegre: Escândalo, 2012.

CAMARGO, Flávio Pereira. Novas configurações familiares na literatura brasileira infantil e juvenil: leitura de Meus dois pais, de Walcyr Carrasco, e de Olivia tem dois papais, de Márcia Leite. In: CONGRESSO INTERNACIONAL DE ESTUDOS LINGUÍSTICOS E LITERÁRIOS NA AMAZÔNIA (CIELLA), 4., 2013, Belém. Anais... Belém: [s.n.], 2013. p. 1-12

CAMINHA, Adolfo. Bom Crioulo. Rio de Janeiro: Edições de Ouro, 2009.

ERIBON, Didier. Reflexões sobre a questão gay. Tradução de Procópio Abreu. Rio de Janeiro: Companhia de Freud, 2008.

FOUCAULT, Michel. Ética, sexualidade e politica. Tradução de Elisa Monteiro; Inês Autran Dourado Barbosa. Rio de Janeiro: Forense Universitária, 2006. 
FOUCAULT, Michel. Vigiar e punir: nascimento da prisão. Tradução de Raquel Ramalhete. Petrópolis: Vozes, 1997.

OLIVA, Osmar Pereira. A terceira margem do desejo: Bom-Crioulo e O Barão de Lavos. In: MOREIRA, Adailson, BEZERRA, Carlos Eduardo; SILVA, Telma Maciel da (Org.). Arco-iris revisitado: diversidade sexual em pauta. Porto Alegre: Escândalo, 2012. p. 215-232.

RICH, A heterossexualidade compulsória e a existência lésbica. Tradução de Carlos Guilherme do Valle. Revista Bagoas, Natal, n. 5, p. 17-44, 2010. Disponível em: <http:/ / www.cchla.ufrn.br/bagoas/v04n05art01_rich. pdf $>$. Acesso em: 5 abr. 2009.

SEDGWICK, Eve Kosofsky. Between Men. In: RIKVIN, J.; RYAN, M. (Ed.) Theory of Literature: an Anthology. Oxford: Blackwell, 1998.

TREVISAN, João Silvério. Introdução à obra Bom Crioulo, de Adolfo Caminha. São Paulo: Hedra, 2009. 